\title{
First report of Leishmania infantum infection in the endangered orangutan (Pongo pygmaeus pygmaeus) in Madrid, Spain
}

Guadalupe Miró ${ }^{*}$, Amelia Troyano², Ana Montoya ${ }^{1}$, Fernando Fariñas ${ }^{3}$, Ma Luisa Fermín ${ }^{4}$, Luís Flores ${ }^{5}$, Carlos Rojo ${ }^{6}$, Rocío Checa ${ }^{1}$, Rosa Gálvez ${ }^{1}$ Valentina Marino ${ }^{1}$, Cristina Fragío ${ }^{4}$ and Eva Martínez-Nevado ${ }^{6}$

\begin{abstract}
Background: Some wild animals have been recognized as potential reservoirs of Leishmania infantum infection (e. g. carnivores, lagomorphs, rodents, etc.). Leishmania infantum was also identified infecting humans and lagomorphs (i.e. hares and rabbits) over the period of 2009-2016, with the latter acting as the main reservoirs involved in the human leishmaniosis outbreak in Madrid.

Results: Two cases of clinical leishmaniosis are reported in orangutans (Pongo pygmaeus pygmaeus) housed at two different centres in Madrid. The first is the case of a 36-year-old male orangutan with severe weight loss and apathy. A complete blood count and biochemical profile revealed anaemia, neutropenia, hypoalbuminaemia and elevated transaminases. Hepato-splenomegaly was also observed. Four months later, due to worsening of clinical signs (mainly bilateral epistaxis), blood and bone marrow samples were collected. Amastigotes of L. infantum were detected in macrophages from a bone marrow aspirate and by specific polymerase chain reaction. The second case was a 34-year-old female orangutan with severe weight loss and apathy and no other apparent clinical signs. A complete blood count and biochemical profile revealed anaemia, pancytopenia and hypoalbuminaemia. Splenomegaly and pericardial effusion were also observed. As leishmaniosis was included in the differential diagnosis, both blood and bone marrow samples were collected. Leishmania infantum infection was confirmed by microscopy, molecular diagnosis and serology (immunofluorescence antibody test). Both animals were treated daily with oral miltefosine for 28 days; allopurinol was also given uninterruptedly in Case 2 for at least 6 months. During follow-up, though good clinical recovery was clear, a lack of parasitological cure was confirmed molecularly in both blood and bone marrow samples from the two orangutans. In both habitats, the presence of the sand fly vector identified as Phlebotomus perniciosus was confirmed.
\end{abstract}

Conclusions: To our knowledge, this is the first report of L. infantum infection in great apes and in the endangered species P. p. pygmaeus. We are presently looking for L. infantum in other non-human primates living in the same periurban areas. If detected, we will examine the impacts of this serious disease on these critically endangered species.

Keywords: Captive wild, Endangered species, Leishmania infantum, Leishmaniosis, Madrid, Orangutans, Pongo pygmaeus pygmaeus, Sand flies

\footnotetext{
*Correspondence: gmiro@ucm.es

'Department of Animal Health, Veterinary Faculty, Universidad Complutense

de Madrid, Madrid, Spain

Full list of author information is available at the end of the article
} 


\section{Background}

Zoonotic leishmaniosis due to Leishmania infantum (syn. L. chagasi) is a vector-borne disease endemic in southern Europe, Asia, North Africa and South America. In Europe, leishmaniosis is spread via the bites of sand flies of the genus Phlebotomus and the disease mainly affects domestic dogs and humans beings, the former being the main reservoir for this infection. In addition to dogs and humans, L. infantum infection has been reported in other European domestic and wild animals such as carnivores [cat (Felis catus), gray wolf (Canis lupus), red fox (Vulpes vulpes), golden jackal (Canis aureus), Iberian lynx (Lynx pardinus), genet (Genetta genetta), mustelids (family Mustelidae), mongoose (family Herpestidae)], lagomorphs, equines (family Equidae), wallaby (Macropus rufogriseus rufogriseus) and rodents) [1-7]. Some of these species are of high conservation value such as housed wallabies in which this infection could have serious impacts on morbidity and/or mortality [3], or the threatened Iberian lynx [8].

Since the first cases of $L$. infantum infection were detected in wallabies (M. r. rufogriseus) in Madrid $[3,9]$, some clinical veterinarians in zoos and wildlife parks have included leishmaniosis in their differential diagnosis protocols for animals living in endemic areas of leishmaniosis or animals that came from endemic areas. Leishmaniosis has been also in the spotlight since, in 2009, the largest human leishmaniosis outbreak in Europe affected the south-west Madrid region [10], where hares (Lepus granatensis) and rabbits (Oryctolagus cuniculus) were confirmed as reservoirs responsible for the transmission of leishmaniosis $[6,7]$. However, the epidemiological role of some wildlife species remains to be established [2, 11-13].

In this study, two cases of $L$. infantum infection in non-human primates (orangutans) are described. As far as we are aware, this is the first description of L. infantum infection in this endangered species.

\section{Methods}

\section{Study area}

The two cases reported here from two orangutans (Pongo pygmaeus pygmaeus) housed in two different centres in Madrid, Spain. Rainfer (Primates Rescue and Rehabilitation Centre) is in the north of the Madrid Autonomous Community $\left(40^{\circ} 32^{\prime} 38.5^{\prime \prime} \mathrm{N}, \quad 3^{\circ} 38^{\prime} 31.0^{\prime \prime W}\right)$. Since its founding in 1995, this centre has been involved in the rescue, rehabilitation and lifelong care of primates in Spain. The centre consists of some 4 ha in the midst of a protected natural environment and hosts 135 primates of 25 different species. The second orangutan is housed at Madrid Zoo within a forested area to the south-west of central Madrid $\left(40^{\circ} 25^{\prime} 22.2^{\prime \prime} \mathrm{N}, 3^{\circ}\right.$ $\left.45^{\prime} 32.0 \mathrm{~W}\right)$. At this zoological park, several protected species are bred and the park hosts over 4000 animals of more than 350 species.

\section{Animals}

The two cases reported were both $P$. p. pygmaeus. The first case was a 36-year-old male orangutan born in 1981 in Rhenen (The Netherlands). In 1994, the animal was transferred to Spain, first to Málaga for 3 years and then in Valencia until it was moved to Rainfer (Madrid) in 2008. The second case was a female orangutan some 34years-old. The animal was born in the Artis Amsterdam Royal Zoo (The Netherlands) and transferred to Madrid Zoo in 2009.

\section{Sample collection}

Prior to clinical examination and sample collection, animals were anesthetised with a combination of $230 \mathrm{mg}$ ketamine plus $2.3 \mathrm{mg}$ medetomidine intramuscular, and oxygen and isoflurane were used as maintenance anaesthesia. Peripheral blood $(5 \mathrm{ml})$ was collected from the cephalic vein into four tubes containing (i) lithium heparin $(1 \mathrm{ml})$ for biochemical profile; (ii) EDTA (0.5 $\mathrm{ml}$ ) for full blood counts and blood smears to detect the presence of any other blood parasites (e.g. Hepatozoan spp., Babesia spp., microfilariae, etc.); (iii) EDTA (1 ml) to assess Leishmania infection by polymerase chain reaction (PCR); and (iv) a tube without additives $(2 \mathrm{ml})$ for serological tests. Blood and serum samples were kept at $4{ }^{\circ} \mathrm{C}$ until processed at the laboratory. Bone marrow from the costochondral joint or iliac crest and/or lymph node aspirates were obtained to prepare smears and were then stored in $200 \mu \mathrm{l}$ of buffer NET $10(\mathrm{NaCl} 10$ mM, EDTA $10 \mathrm{mM}$,Tris $10 \mathrm{mM}$ ). All samples for DNA extraction were stored at $-20{ }^{\circ} \mathrm{C}$ until further analysis.

\section{Assessment of Leishmania infection Microscopy}

Giemsa-stained bone marrow smears were examined by light microscopy $(\times 400$ and $\times 1000$ magnification) to assess the presence of Leishmania spp. amastigotes in macrophages.

\section{Serum antibody testing}

For serological tests, specific antibodies to Leishmania spp. were detected using the indirect immunofluorescence antibody test (IFAT) against in-house cultured promastigotes. The IFAT for anti-Leishmania-specific immunoglobulin G (IgG) antibodies was performed with an anti-human IgG fluorescein conjugate as described previously [14] using a cut-off of $\geq 1: 100$ to define seropositivity. 


\section{Molecular analysis}

Genomic DNA was isolated from peripheral blood and tissue samples using the QIAamp ${ }^{\circ}$ DNA mini kit (Qiagen, Hilden, Germany) according to the manufacturer's instructions. The starting material was either $200 \mu \mathrm{l}$ of blood or $20 \mathrm{mg}$ of tissue. Obtained DNA was eluted in $200 \mu \mathrm{l}$ molecular-grade water for blood and tissue samples. DNA samples were stored at $-20^{\circ} \mathrm{C}$ until use.

For Leishmania detection and species identification, a $20 \mu \mathrm{l}$ aliquot of eluted DNA was used for each PCR. The parasite was detected using a nested PCR protocol by amplification of a portion of the ITS-1 gene according to the protocol described by Schönian et al. [15] but slightly modified. This protocol is Leishmania genusspecific and uses the primer pair LITSR (5'-CTG GAT CAT TTT CCG ATG-3')/ L5.8S (5'-TGA TAC CAC TTA TCG CAC TT-3') in the first reaction. In the second mixture, the starting primers were replaced with the primers SAC (5'-CAT TTT CCG ATG ATT ACA CC-3') and VAN2 (5'-GCG ACA CGT TAT GTG AGC CG-3'). The PCR amplification product (280-330 bp) was visualised using a dark reader trans-illuminator (Clare Chemicals, Colorado, USA).

\section{DNA sequencing}

Leishmania-positive ITS1 PCR products corresponding to the expected length were excised from agarose gels and purified using the QIAquick Gel ExtractionKit (Qiagen) as described by the manufacturer. The products were sequenced with the corresponding forward and reverse primers at the sequencing service of the Genomics department, UCM, using an ABI Prism 3730 system (Applied Biosystems, California, USA).

Sequence chromatogram files were analysed using Chromas 2.1.1 and imported into BioEdit v.7.0.5 for editing, assembly and alignments. The sequences obtained were aligned with sequences available from GenBank using Clustal W and compared with additional Leishmania spp. sequences available from GenBank using the BLAST program (http://blast.ncbi.nlm.nih.gov/Blast.cgi) to determine percentage identities of the generated sequences against published sequences.

\section{Entomological data}

A preliminary entomological survey was carried out in the orangutans' environment at the two centres. In July 2017 and in October 2017, five miniature light traps [Model 2836BQ, improved version of the mosquito light trap developed by the Centers for Disease Control $(\mathrm{CDC})]$ were set-up at each site overnight. Traps were placed in the afternoon and recovered early in the morning. Collected sand flies were kept in $70 \%$ ethanol until processing. At the laboratory, females were cleared in Mark André medium [16], mounted on glass slides in
Hoyer medium [17], and species identified using identification keys [18].

\section{Results \\ Case 1}

The male orangutan was examined in December 2016 due to a clinical picture characterised by severe weight loss and apathy. A complete blood count and biochemical profile revealed regenerative anaemia (red blood cell count $=2.84 \times 10^{12} / \mathrm{l}$; haematocrit of $25.1 \%$ ), leucocytopenia (white blood cell count $=3.2 \times 10^{9} / \mathrm{l}$ ) hypoalbuminaemia $(2.4 \mathrm{~g} / \mathrm{dl})$ and elevated transaminases $(\mathrm{ALT}=51$ $\mathrm{U} / \mathrm{l}$ AST $=66 \mathrm{U} / \mathrm{l})$. Hepato-splenomegaly was also observed by abdominal ultrasonography. The initial differential diagnosis included autoimmune haemolytic anaemia and vector borne diseases, and the recommended treatment was palliative consisting of oral vitamin C $(500 \mathrm{mg} / 24 \mathrm{~h})$, doxycycline $(200 \mathrm{mg} / 24 \mathrm{~h})$, folic acid (5 mg/24h), paracetamol (500 mg/12 h), omeprazole $(20 \mathrm{mg} / \mathrm{kg}$ ) and prednisone (35 mg/12 h). In March 2017, due to worsening of clinical signs (mainly bilateral epistaxis), blood and bone marrow samples were collected. The same haematological and biochemical abnormalities were observed as initially, and this timeleishmaniosis was included in our differential diagnosis and consequently $L$. infantum amastigotes were detected in bone marrow aspirate macrophages. Four months later (June 2017) specific PCR conducted in stored blood samples confirmed the diagnosis.

The animal was treated daily with oral miltefosine $(2.5$ $\mathrm{mg} / \mathrm{kg} /$ day for 28 days), omeprazole, prednisone and a vitamin complex (B, C, D and $\mathrm{K})$. In addition, metronidazole $(250 \mathrm{mg})$ and spiramycin (1.5 M IU) combination (PO BID for 2 weeks) treatment was given for an infected tooth.

Following the miltefosine-based treatment, the animal started to gain weight and its general health condition improved. Three months later (July 2017), haematological and biochemical tests were repeated, observing normalised variables except for hepatic enzymes. Hepatomegaly was also observed by ultrasonography. The parasitological results are shown in Table 1. Currently, the animal's general clinical status is stable.

\section{Case 2}

In May 2017, the female orangutan was examined because of severe weight loss and apathy with no other apparent clinical signs. A complete blood count and biochemical profile revealed anaemia (red blood cell count $=2.18 \times$ $10^{12} / \mathrm{l}$; haematocrit of $16.3 \%$; haemoglobin $4.1 \mathrm{~g} / \mathrm{dl}$ ), pancytopenia (white blood cell count $=0.538 \times 10^{9} / \mathrm{l}$; platelets $\left.=77.5 \times 10^{9} / \mathrm{l}\right)$ and hypoalbuminaemia $(2.4 \mathrm{~g} / \mathrm{dl})$. Supportive treatment was given consisting of blood transfusion (from a healthy adult male of the same group) and 
Table 1 Clinical signs, serology and PCR test results recorded in the two orangutans (Pongo pygmaeus pygmaeus) examined in this study

\begin{tabular}{|c|c|c|c|c|c|}
\hline \multirow{2}{*}{$\begin{array}{l}\text { Animal description } \\
\text { Dates of screening }\end{array}$} & \multicolumn{3}{|l|}{ Case 1 , male, 36 years } & \multicolumn{2}{|c|}{ Case 2 , female, 34 years } \\
\hline & $\begin{array}{l}\text { December } 2016 \\
\text { (before diagnosis) }\end{array}$ & $\begin{array}{l}\text { March } 2017 \\
\text { (diagnosis) }\end{array}$ & $\begin{array}{l}\text { July } 2017 \\
\text { (after treatment) }\end{array}$ & $\begin{array}{l}\text { June } 2017 \\
\text { (diagnosis) }\end{array}$ & $\begin{array}{l}\text { October } 2017 \\
\text { (after treatment) }\end{array}$ \\
\hline Clinical signs & $\begin{array}{l}\text { Weight loss, apathy, } \\
\text { hepato-splenomegaly }\end{array}$ & $\begin{array}{l}\text { Weight loss, apathy, } \\
\text { hepato-splenomegaly, } \\
\text { bilateral epistaxis }\end{array}$ & Hepatomegaly & $\begin{array}{l}\text { Weight loss, apathy, } \\
\text { splenomegaly, } \\
\text { pericardial effusion }\end{array}$ & $\begin{array}{l}\text { No signs, } \\
\text { no weight gain }\end{array}$ \\
\hline \multicolumn{6}{|l|}{ CBC [reference values (ZIMS)] } \\
\hline $\begin{array}{l}\text { Red blood count (3.62-5.89) } \\
\times 10^{12} / \mid\end{array}$ & 2.84 & 2.78 & 4.68 & 2.18 & 3.09 \\
\hline Haematocrit (29.0-44.9) \% & 25.1 & 21.1 & 41.8 & 16.3 & 20.3 \\
\hline Haemoglobin (8.9-13.9) g/dl & 7.5 & 6.2 & 11.5 & 4.1 & 5.4 \\
\hline $\begin{array}{l}\text { White blood count (3.8-17) } \\
\times 10^{9} / 1\end{array}$ & 3.2 & 2.0 & 8.1 & 0.538 & 0.42 \\
\hline Platelets $(84-309) \times 10^{9} / 1$ & 101 & 60 & 142 & 77.5 & 76.3 \\
\hline \multicolumn{6}{|l|}{ BP [reference values (ZIMS)] } \\
\hline Albumin $(3.0-5.2) \mathrm{g} / \mathrm{dl}$ & 2.4 & 2.1 & 2.7 & 2.1 & 2.4 \\
\hline ALT (6-43) U/L & 51 & 76 & 41 & 17 & 20 \\
\hline AST (4-33) U/L & 66 & 106 & 33 & 18 & 37 \\
\hline Serology results (IFAT) & $1 / 200$ & $1 / 400$ & $1 / 200$ & $1 / 400$ & $1 / 200$ \\
\hline $\begin{array}{l}\text { Bone marrow cytology } \\
\text { (microscopy) }\end{array}$ & nt & POS & NEG & POS & NEG \\
\hline \multicolumn{6}{|l|}{ PCR results } \\
\hline Peripheral blood & POS & POS & $\mathrm{nt}$ & POS & POS \\
\hline Bone marrow & nt & nt & POS & POS & POS \\
\hline
\end{tabular}

Abbreviations: CBC complete blood counts, BP biochemical profile, POS positive, NEG negative, $n t$ not tested, IFAT immunofluorescence antibody test, ZIMS Species 360 (Zoological Information Management System 2017) [43]

omeprazole $40 \mathrm{mg}$ per os (PO), once daily (SID), ferrous sulphate $80 \mathrm{mg}$ PO SID, doxycycline $100 \mathrm{mg}$ PO SID and $500 \mathrm{mg}$ paracetamol PO BID. Splenomegaly and pericardial effusion were also observed. A second intervention was planned for bone marrow collection. Leishmaniosis was included in the differential diagnosis and both blood and bone marrow aspirates were collected. L. infantum infection was confirmed by microscopy, molecular diagnosis and serology (IFAT) (see Table 1).

The orangutan was treated daily with oral miltefosine ( $2.5 \mathrm{mg} / \mathrm{kg}$ PO SID) for 28 days, and with allopurinol (300 mg PO BID) and vitamin complex indefinitely (at least 6 months).

During follow-up (3 months later, October 2017), though good clinical recovery was evident, haematological and biochemical variables were similar to pretreatment values (red blood cell count $=3.09 \times 10^{12} / \mathrm{l}$; haematocrit of $20.3 \%$; haemoglobin $5.4 \mathrm{~g} / \mathrm{dl}$; white blood count $=0.42$ $\times 10^{9} / \mathrm{l}$; platelets $=76.3 \times 10^{9} / \mathrm{l}$ : albumin $2.4 \mathrm{~g} / \mathrm{dl}$; globulin $4.6 \mathrm{~g} / \mathrm{dl}$; albumin/globulin 0.5). A lack of parasitological cure was confirmed molecularly in both the blood and bone marrow samples (see Table 1).

Lastly, despite no apathy there was still no weight gain and we administered a second cycle of oral miltefosine (for December 2017, 4 months after the first cycle). To date, the animal continues with the same oral daily dose of allopurinol for at least 6 months.

\section{Sequencing results}

The concatenated ITS sequence was 259 and $260 \mathrm{bp}$ for Case 1 and 2, respectively. Both sequences were 99\% identical to the L. infantum isolate MHOM/ES/87/Lombardi strain sequence (GenBank: AJ000295). These results are consistent with the infection of both orangutans with this strain. This causative agent was recently identified in Bennett's wallabies (M. r. rufogriseus) kept in a wildlife park in Madrid, Spain [3] and in reported cases of the disease in humans and hares as the result of the leishmaniosis outbreak in the Madrid region [19].

\section{Entomological data}

In both habitats, the presence of the sand flies was confirmed. At Rainfer (habitat of Case 1), 7 sand fly specimens were captured on October 3rd around the orangutan's habitat: 4 Phlebotomus perniciosus (1 female and 3 males) and 3 Sergentomyia minuta (2 females and 1 male). At the Madrid Zoo (habitat of Case 2), 17 sand fly specimens were captured on July 10th around the 
orangutan's habitat: 15 P. perniciosus (3 females and 12 males), 1 Phlebotomus papatasi (1 male) and 1 S. minuta (1 male). The most frequent vector of $L$. infantum in Spain, $P$. perniciosus, was detected in the two places surveyed. We observed one engorged $P$. perniciosus female at Rainfer and another one at the Madrid Zoo.

\section{Discussion}

To our knowledge, this report describes the first two clinical cases of leishmaniosis in orangutans (P. p. pygmaeus) and is the first notification of $L$. infantum infection in non-human primates (NHP) in Spain. Descriptions exist in Brazil of Leishmania infection in NHP. In one report, a black-fronted titi monkey (Callicebus nigrifrons) developed a fatal disease with clinical signs and lesions compatible with leishmaniosis; $L$. infantum (syn. L. chagasi) was confirmed by PCR and immunohistochemistry [12]. In another case in Bauru, São Paulo, Brazil, Leishmania amazonensis was detected by molecular methods in blood samples from a captive spider monkey (Ateles paniscus), which showed weight loss and pale mucous membranes [20].

Malta et al. [12] also detected L. infantum by PCR in blood samples from NHP housed in a zoo in Belo Horizonte (State of Minas Gerais, Brazil): six black-fronted titi monkeys (C. nigrifrons), one howler monkey (Alouatta guariba), three golden-bellied capuchins (Cebus xanthosternos), one golden-headed lion tamarin (Leontopithecus crysomelas), one black-headed owl monkey (Aotus nigriceps), two Rio Tapajos' sakis (Pithecia irrorata) and three emperor tamarins (Saguinus imperator). These 17 NHP showed no clinical signs of disease. As indicated in a study conducted by Carneiro et al. [21], these infected primates were clinically healthy. Carneiro et al. hypothesized that New World primates have developed an innate immune response mechanism capable of controlling macrophage intracellular growth of L. infantum [21]. However, several field studies have confirmed a high susceptibility to Leishmania spp. infection with cutaneous signs in owl monkeys (Atous trivirgatus) and Geoffroy's tamarins (Saguinus geoffroyi) [22], while in tufted capuchin monkeys (Cebus paella) and bearded sakis (Chiropotes satanus), visceral leishmaniosis [23, 24] was confirmed. In addition, experimental studies have observed fulminating visceral leishmaniosis both in Neotropical [owl monkeys (Atous trivirgatus), tufted capuchin monkeys (Cebus paella), (Callithrix jacchus jacchus), squirrel monkeys (Saimiri sciureus)] and Old World monkeys [common marmoset vervet monkeys (Cercopithecus aethiops), rhesus macaques (Macaca mullata), and langur monkeys (Presbytis entellus)] [25-31].

Despite our confirmation of two cases of clinical leishmaniosis in orangutans in Madrid, the role of this species in transmitting this zoonotic disease will remain unknown until future xenodiagnostic studies are carried out.

Our results indicate the high presence of Leishmania in the environment (there may be many potential reservoirs and sand flies sharing the same habitat), since two orangutans became infected. Accordingly, there will be a risk of $L$. infantum transmission to other susceptible animals living in nearby areas as well as to humans. After all, these animals are living in an urban environment in close contact with humans, possibly posing a public health risk. Some authors have argued that wild animals may act as sentinels indicating the risk of zoonoses, and highlighting the importance of the 'One Health' concept [32-35].

Our preliminary entomological survey revealed the presence of $P$. perniciosus in the nearby environment of the orangutans. A more exhaustive survey is needed during the active period of this phlebotomine. This would enable us to look for infected phlebotomines in larger numbers of captured $P$. perniciosus at both sites and determine their blood-feeding preferences on several possible hosts by using molecular tools.

Orangutans are considered critically endangered species according to the IUCN [36]. Both of the present orangutans are included in the EEP (European Endangered Species Programme) of EAZA (European Association of Zoos and Aquaria) [36] targeted at maintaining healthy populations of animals in captivity while safeguarding their genetic health. The morbidity and mortality of these animals is not only a dramatic situation for an animal reserve or zoo, but also for the future breeding and conservation of these species [37]. Efforts are thus needed to avoid infection by L. infantum in these species through early diagnostics and the use of preventative measures in these environments as well as on animals (e.g. topical pyrethroid formulations). More extensive entomological surveys are needed to effectively design insecticide control measures applied to the environment. Besides, in captive wild animals, it is also necessary to control stress and any disease that could compromise the immune system and lead to clinical leishmaniosis in infected animals [12].

Although, there are no data available regarding the treatment of leishmaniosis in NHP, we opted for miltefosine due to its easier administration (oral route) and its effectiveness observed in human medicine studies for the treatment of visceral leishmaniosis [38]. We should not, however, forget about the risk of resistance when this drug is used as monotherapy, as suggested in studies conducted in India $[39,40]$ and in immunocompromised patients [41, 42].

Finally, we should highlight the importance of including $L$. infantum infection in the differential diagnosis list for captive wild animals (especially endangered species) 
with clinical signs or laboratory abnormalities compatible with this disease living in endemic areas.

\section{Conclusions}

To our knowledge, this is the first report worldwide of $L$. infantum infection in great apes and in Pongo pygmaeus pygmaeus. As the presence of the sand fly vector was also confirmed in the orangutans' habitat, our results suggest the possible detection of L. infantum in other non-human primates living in this endemic area, which may be a risk for endangered species living in captivity.

\section{Abbreviations}

ALT: Alanine aminotransferase; AST: Aspartate aminotransferase; BID: Twice a day; EAZA: European Association of Zoos and Aquaria;

EDTA: Ethylenediaminetetra-acetic acid; EEP: European Endangered Species Programme; g/dl: grams per decilitre; IFAT: Indirect immunofluorescence antibody test; IU: International units; NHP: Non-human primate;

PCR: Polymerase chain reaction; PO: Per os; SID: Once a day; U/I: Unit per litre

\section{Acknowledgements}

Publication of this paper has been sponsored by Bayer Animal Health in the framework of the 13th CVBD World Forum Symposium.

\section{Funding}

Not applicable.

\section{Availability of data and materials}

All data generated or analysed during this study are included in this published article.

\section{Authors' contributions}

GM conceived and coordinated the study, participated in its design and the field study, and drafted and finalised the manuscript. AT as Rainfer's veterinarian carried out sample collection, applied treatments and followedup clinical case number 1. LF acted as advisor for Rainfer. EMN and CR as Madrid Zoo's veterinarians carried out sample collection, applied treatments and followed-up case number 2 and EMN drafted and finalised the manuscript. AM participated in the diagnostic assays, drafted the first version of the manuscript and finalised the manuscript. FF performed the early microscopic diagnosis of case number 1. MLF and CF carried out the samples collections and performed microscopic diagnosis of case number 2. RC carried out the molecular procedures and helped with the manuscript draft. RG performed the entomological study and reviewed the final manuscript. VM helped with the laboratory work and data collection. All authors read and approved the final manuscript.

\section{Ethics approval}

Animals were kept and handled according to animal welfare standards. The study was carried out in accordance with International Guiding Principles for Biomedical Research Involving Animals and Spanish Legislation (Law 31/2003 and RD 53/2013).

\section{Consent for publication}

Not applicable.

\section{Competing interests}

The authors declare that they have no competing interests.

\section{Publisher's Note}

Springer Nature remains neutral with regard to jurisdictional claims in published maps and institutional affiliations.

\section{Author details}

'Department of Animal Health, Veterinary Faculty, Universidad Complutense de Madrid, Madrid, Spain. 'Centro de Rescate de Primates "RAINFER", Fuente del Saz, Madrid, Spain. ${ }^{3}$ Institute of Clinical Immunology and Infectious
Diseases, Málaga, Spain. ${ }^{4}$ Department of Animal Medicine and Surgery, Veterinary Faculty, Universidad Complutense de Madrid, Madrid, Spain ${ }^{5}$ Centre de Rehabilitation des Primates de Lwiro, Lwiro Village, South Kivu, Democratic Republic of Congo. ${ }^{6}$ Zoo de Madrid, Casa de Campo s/n, 28011 Madrid, Spain

Received: 11 December 2017 Accepted: 6 March 2018

Published online: 20 March 2018

\section{References}

1. Solano-Gallego L, Fernández-Bellon H, Serra R, Gállego M, Ramis A, Fondevila $\mathrm{D}$, et al. Cutaneous leishmaniosis in three horses in Spain. Equine Vet J. 2003;35:320-3.

2. Millán J, Ferroglio E, Solano-Gallego L. Role of wildlife in the epidemiology of Leishmania infantum infection in Europe. Parasitol Res. 2014;113:2005-14.

3. Montoya A, de Quadros LP, Mateo M, Hernández L, Gálvez R, Alcántara G, et al. Leishmania infantum infection in Bennett's wallabies (Macropus rufogriseus rufogriseus) in a Spanish wildlife park. J Zoo Wildl Med. 2016:47: 586-93.

4. Gama A, Elias J, Ribeiro AJ, Alegria N, Schallig HD, Silva F, et al. Cutaneous leishmaniosis in a horse from northern Portugal. Vet Parasitol. 2014;200:189-92.

5. Tsakmakidis I, Angelopoulou K, Dovas Cl, Dokianakis E, Tamvakis A Symeonidou I, et al. Leishmania infection in rodents in Greece. Tropical Med Int Health. 2017:22(12):1523-32.

6. Molina R, Jiménez MI, Cruz I, Iriso A, Martín-Martín I, Sevillano O, et al. The hare (Lepus granatensis) as potential sylvatic reservoir of Leishmania infantum in Spain. Vet Parasitol. 2012;190:268-71.

7. García N, Moreno I, Alvarez J, de la Cruz ML, Navarro A, Pérez-Sancho M, et al. Evidence of Leishmania infantum infection in rabbits (Oryctolagus cuniculus) in a Natural Area in Madrid, Spain. Biomed Res Int. 2014;2014: 318254

8. Palomares F, Rodríguez A, Revilla E, López-Bao JV, Calzada J. Assessment of the conservation efforts to prevent extinction of the Iberian lynx. Conserv Biol. 2011;25:4-8.

9. Ramírez GA, Peñafiel-Verdú C, Altimira J, García-González B, Vilafranca M. Naturally acquired visceral leishmaniosis in a captive Bennett's wallaby (Macropus rufogriseus rufogriseus). Vet Pathol. 2013:50:188-90.

10. Arce A, Estirado A, Ordobas M, Sevilla S, García N, Moratilla L, et al. Reemergence of leishmaniasis in Spain: community outbreak in Madrid, Spain 2009 to 2012. Euro Surveill. 2013;18:20546.

11. Luppi MM, Malta MCC, Silva TMA, Silva FL, Motta ROC, Miranda I, et al. Visceral leishmaniasis in captive wild canids in Brazil. Vet Parasitol. 2008;155: 146-51.

12. Malta MCC, Tinoco HP, Xavier MN, Vieira ALS, Costa EA, Santos RL. Naturally acquired visceral leishmaniasis in non-human primates in Brazil. Vet Parasitol. 2010;169:193-7.

13. Quinnell RJ, Courtenay O. Transmission, reservoir hosts and control of zoonotic visceral leishmaniasis. Parasitology. 2009:136:1915-34

14. Deniau M, Cañavate C, Faraut-Gambarelli F, Marty P. The biological diagnosis of leishmaniasis in HIV-infected patients. Ann Trop Med Parasitol. 2003;97(Suppl. 1):115-33

15. Schönian G, Nasereddin A, Dinse N, Schweynoch C, Schallig HDFH, Presber W, et al. PCR diagnosis and characterization of Leishmania in local and imported clinical samples. Diagn Microbiol Infect Dis. 2003:47:349-58.

16. Abonnenc E. Les phlébotomes de la région éthiopienne (Diptera, Psychodidae). Paris: ORSTOM; 1972. p. 289.

17. Upton MS. Aqueous gum-chloral slide mounting media: an historical review. Bull Entomol Res. 1993;83:267-74.

18. Gil Collado J, Morillas Márquez F, Sanchis Marín MC. Los flebotomos en España. Rev Sanid Hig Publica Madr. 1989;63:15-3.

19. Chicharro C, Llanes-Acevedo I, Garcia E, Nieto J, Moreno J, Cruz I. Molecular typing of Leishmania infantum isolates from a leishmaniasis outbreak in Madrid, Spain, 2009 to 2012. Euro Surveill. 2013:18(30):20545.

20. Lima VM, Santiago ME, Sanches Lda C, Lima BD. Molecular diagnosis of Leishmania amazonensis in a captive spider monkey in Bauru, São Paulo, Brazil. J Zoo Wildl Med. 2012;43:943-5.

21. Carneiro LA, Laurenti MD, Campos MB, Gomes CM, Corbett CEP, Silveira FT. Susceptibility of peritoneal macrophage from different species of neotropical primates to ex vivo Leishmania (L.) infantum chagasi-infection. Rev Inst Med Trop Sao Paulo. 2012;54:95-101. 
22. Herrer A, Christensen HA, Beumer RJ. Reservoir hosts of cutaneous leishmaniasis among Panamanian forest mammals. Am J Trop Med Hyg. 1973;22:585-91

23. Lainson R, Braga RR, De Souza AA, Pôvoa MM, Ishikawa EA, Silveira FT. Leishmania (Viannia) shawi sp. n., a parasite of monkeys, sloths and procyonids in Amazonian Brazil. Ann Parasitol Hum Comp. 1989;64:200-7.

24. Lainson R, Shaw JJ, Braga RR, Ishikawa EA, Souza AA, Silveira FT. Isolation of Leishmania from monkeys in the Amazon Region of Brazil. Trans R Soc Trop Med Hyg. 1988;82:231.

25. Chapman WL, Hanson WL, Hendricks LD. Leishmania donovani in the owl monkey (Aotus trivirgatus). Trans R Soc Trop Med Hyg. 1981;75:124-5.

26. Chapman WL, Hanson WL. Visceral leishmaniasis in the squirrel monkey (Saimiri sciurea). J Parasitol. 1981;67:740-1.

27. Marsden PD, Cuba CC, Vexenat A, Costa e Silva M, Costa e Silva A, Barreto AC. Experimental Leishmania chagasi infections in the marmoset Callithrix jacchus jacchus. Trans R Soc Trop Med Hyg. 1981;75:314-5.

28. Porrozzi R, Pereira MS, Teva A, Volpini AC, Pinto MA, Marchevsky RS, et al. Leishmania infantum-induced primary and challenge infections in rhesus monkeys (Macaca mulatta): a primate model for visceral leishmaniasis. Trans R Soc Trop Med Hyg. 2006;100:926-37.

29. Dube A, Srivastava JK, Sharma P, Chaturvedi A, Katiyar JC, Naik S. Leishmania donovani: cellular and humoral immune responses in Indian langur monkeys, Presbytis entellus. Acta Trop. 1999;73:37-48.

30. Gicheru MM, Olobo JO, Kariuki TM, Adhiambo C. Visceral leishmaniasis in vervet monkeys: immunological responses during asymptomatic infections. Scand J Immunol. 1995:41:202-8.

31. Grimaldi G Jr. The utility of rhesus monkey (Macaca mulatta) and other non-human primate models for preclinical testing of Leishmania candidate vaccines. Mem Inst Oswaldo Cruz. 2008;103:629-44.

32. Thompson RC. Parasite zoonoses and wildlife: One Health, spillover and human activity. Int J Parasitol. 2013;43:1079-88.

33. Aguirre AA. Wild canids as sentinels of ecological health: a conservation medicine perspective. Parasit Vectors. 2009;2(Suppl. 1):S7.

34. Scotch M, Odofin L, Rabinowitz P. Linkages between animal and human health sentinel data. BMC Vet Res. 2009:5:15.

35. Souza TD, Turchetti AP, Fujiwara RT, Paixão TA, Santos RL. Visceral leishmaniasis in zoo and wildlife. Vet Parasitol. 2014;200:233-41.

36. European Association of Zoos and Aquaria. Specialist Programmes. http:// www.eaza.net/conservation/programmes/\#BPG. 2017. Accessed 8 Nov 2017.

37. Strong VJ, Grindlay D, Redrobe S, Cobb M, White K. A Systematic review of the literature relating to captive great ape morbidity and mortality. J Zoo Wildl Med. 2016;47:697-710.

38. Guerin PJ, Olliaro P, Sundar S, Boelaert M, Croft SL, Desjeux P, et al. Visceral leishmaniasis: current status of control, diagnosis, and treatment, and a proposed research and development agenda. Lancet Infect Dis. 2002;2:494-501.

39. Hefnawy A, Berg M, Dujardin J-C, De Muylder G. Exploiting knowledge on Leishmania drug resistance to support the quest for new drugs. Trends Parasitol. 2017;33:162-74.

40. Sundar S, Singh A, Rai M, Prajapati VK, Singh AK, Ostyn B, et al. Efficacy of miltefosine in the treatment of visceral leishmaniasis in India after a decade of use. Clin Infect Dis. 2012;55:543-50.

41. Monge-Maillo B, López-Vélez R. Treatment options for visceral leishmaniasis and HIV coinfection. AIDS Rev. 2016;18:32-43.

42. Copeland NK, Aronson NE. Leishmaniasis: treatment updates and clinical practice guidelines review. Curr Opin Infect Dis. 2015;28:426-37.

43. Zoological Information Management System (ZIMS) for Studbooks. Species360. 2006. https://www.species360.org/products-services/zims-forstudbooks/. Accessed 7 Feb 2018

\section{Submit your next manuscript to BioMed Central and we will help you at every step:}

- We accept pre-submission inquiries

- Our selector tool helps you to find the most relevant journal

- We provide round the clock customer support

- Convenient online submission

- Thorough peer review

- Inclusion in PubMed and all major indexing services

- Maximum visibility for your research

Submit your manuscript at www.biomedcentral.com/submit 